\title{
The prognostic value of long non coding RNAs in cervical cancer: A meta-analysis
}

\author{
Xiangrong Cui ${ }^{1, *}$, Xuan Jing ${ }^{2, *}$ and Xueqing $\mathbf{W} \mathbf{u}^{1}$ \\ ${ }^{1}$ Reproductive Medicine Center, Children's Hospital of Shanxi and Women Health Center of Shanxi, Affiliate of Shanxi Medical \\ University, Taiyuan, 030000, P.R. China \\ ${ }^{2}$ Clinical Laboratory, Shanxi Provincial People's Hospital, Affiliate of Shanxi Medical University, Taiyuan, 030012, P.R. China \\ *These authors contributed equally to this work
}

Correspondence to: Xueqing Wu, email: xueqingwu416@163.com

Keywords: IncRNA, cervical cancer, prognosis, biomarker, meta-analysis

Received: February 28, $2017 \quad$ Accepted: April 21, $2017 \quad$ Published: May 04, 2017

Copyright: Cui et al. This is an open-access article distributed under the terms of the Creative Commons Attribution License 3.0 (CC BY 3.0 ), which permits unrestricted use, distribution, and reproduction in any medium, provided the original author and source are credited.

\section{ABSTRACT}

Cervical cancer is one of the most common malignancies in women worldwide. Numerous literatures demonstrate that aberrantly expressed IncRNAs are involved in tumorigenesis and development, and may have the potential to be prognostic markers. However, their prognostic functions in cervical remain controversial. Therefore, we performed this meta-analysis to evaluate the prognostic significance of IncRNAs in cervical cancer. We searched databases to identify relevant articles. Pooled hazard ratios (HRs) and 95\% confidence intervals (CIs) were calculated. 15 studies involving 1868 patients with cervical cancer and 12 IncRNAs were included. Our results indicated that the levels of IncRNAs were associated with the overall survival ( ( HR $=1.56,95 \% C I=1.02-2.38, P<0.001$, random-effect $)$ and event free survival (HR $=1.33,95 \% \mathrm{CI}=0.77-2.28, P<0.01$, random-effect). High HOTAIR expression was associated with shorter overall survival in cervical cancer ( $H R=3.93,95 \%$ CI $=$ 2.34-6.62, $P<0.001$, fixed-effect). In conclusion, our meta-analysis suggested that IncRNAs may serve as novel predictive factors for prognosis of cervical and high expression HOTAIR was associated with shorter overall survival in cervical cancer.

\section{INTRODUCTION}

Cervical cancer is the second most deadly gynecological cancer and caused about 260,000 women's death each year [1]. Radical surgery is recommended as the preferred treatment for patients with cervical cancer in early stage, producing a relatively favorable prognosis [2]. However, patients with cervical cancer are usually diagnosed at advanced or recurrent stages with relatively poor prognosis [3]. Hence, exploring sensitive and specific biomarkers for prognosis is critical for the research and clinical treatment of cervical cancer.

Long noncoding RNA (lncRNA) are a kind of non-coding transcripts longer than 200 nucleotides [4]. LncRNAs can regulate various biological processes, such as gene expression, transcription, and cellular proliferation, through epigenetic silencing, mRNA splicing, and lncRNA-microRNA interaction [5, 6]. Furthermore, by comparing their expression of tumors and normal cells, IncRNAs are abnormally expressed in the various tumors, functioning as oncogenes or tumor suppressors $[7,8]$. Recent studies have shown that lncRNAs also play important role in cervical cancer, including occurrence, progression, metastasis and prognosis $[9,10]$. However, due to the sample size and research programs, singe study may be inaccurate and insufficient. With the aim to obtain a better understanding of the prognostic value of lncRNAs in patients with cervical cancer, we performed a meta-analysis to explore the prognostic value of lncRNAs through larger sample size of patients. 


\section{RESULTS}

\section{Study characteristics}

As shown in Figure 1, we searched 191 articles in the databases. After screening the titles and abstracts, 29 full-text articles were assessed for eligibility. Then because of no usable data or incomplete data, 14 papers were excluded. As a result, a total of 15 articles were the current meta-analysis [11-25].

The basic information and data from the included studies are shown in Table 1 and Table 2. 15 studies enrolling 1868 participants, with a maximum sample size of 218 and a minimum sample size of 49 patients. Among these 15 studies, 14 focused on Asians and 1 evaluated Caucasians. 9 studies reported patient overall survival (OS), 2 focused on OS as well as disease free survival (DFS), and 5 investigated OS as well as relapse free survival (RFS). DFS and RFS were combined together into event free survival (EFS) as prognosis parameter of our study. All studies investigated patients with cervical cancer and qRT-PCR was performed to detect IncRNAs expression in tumor tissues. Because the cut-off definitions were various, the cut-off values were different in these studies.

\section{Analysis between IncRNAs expression level and OS}

A total of 15 studies were reported that the expression levels of lncRNAs were related to OS. The random-effect model was used to assess the HRs and $95 \%$ CI. As shown in Figure 2, the expression levels of lncRNAs were associated with the OS of cervical cancer patients (HR = $1.56,95 \% \mathrm{CI}=1.02-2.38, P<0.001$, random-effect). From the forest plot, the high expressions of HOTAIR, PVT1, GAS5, MALAT1, CCHE1, HULC, HOXA11, ANRIL were associated with poor prognosis. Besides, XLOC_010588, XIST, LET, MEG3 were correlated to poor prognosis with the low expressions of IncRNAs in cervical cancer. With all the IncRNAs HOTAIR generate the highest HR of 5.28 [16]; by contrast, XIST exhibited the lowest HR of 0.27 [17]. Moreover, stratified analyses were performed using studies with the ethnicity. 14 articles reported the relationship between lncRNAs and Asian patents' OS (HR $=1.54$, 95\% CI $=0.96-2.47, P<0.01$, random-effect), and 1article was about Caucasian $(\mathrm{HR}=1.73,95 \% \mathrm{CI}=1.05-2.85$, $P=0.03$, fixed-effect).

In the enrolling studies, HOTAIR and PVT1 were investigated in two or more articles, other IncRNAs were performed in single study. Then we carried out a metaanalysis on the relationship between the expressions of HOTAIR/PVT1 and the OS of patients with cervical cancer. We found that the high levels of HOTAIR were associate with a poor OS $(\mathrm{HR}=3.93,95 \% \mathrm{CI}=2.34-6.62, P<0.001$, fixed-effect) (Figure 3A). Meanwhile, a poor prognosis in cervical cancer was found in the increased of PVT1 $(\mathrm{HR}=$ $1.84,95 \% \mathrm{CI}=1.27-2.65, P=0.01$, fixed-effect) (Figure 3B)

\section{Analysis between IncRNAs expression level and EFS}

A total of 6 studies (912 patients) included in the EFS analysis revealed a protective role increased lncRNAs expression $(\mathrm{HR}=1.33,95 \% \mathrm{CI}=0.77-2.28, P$

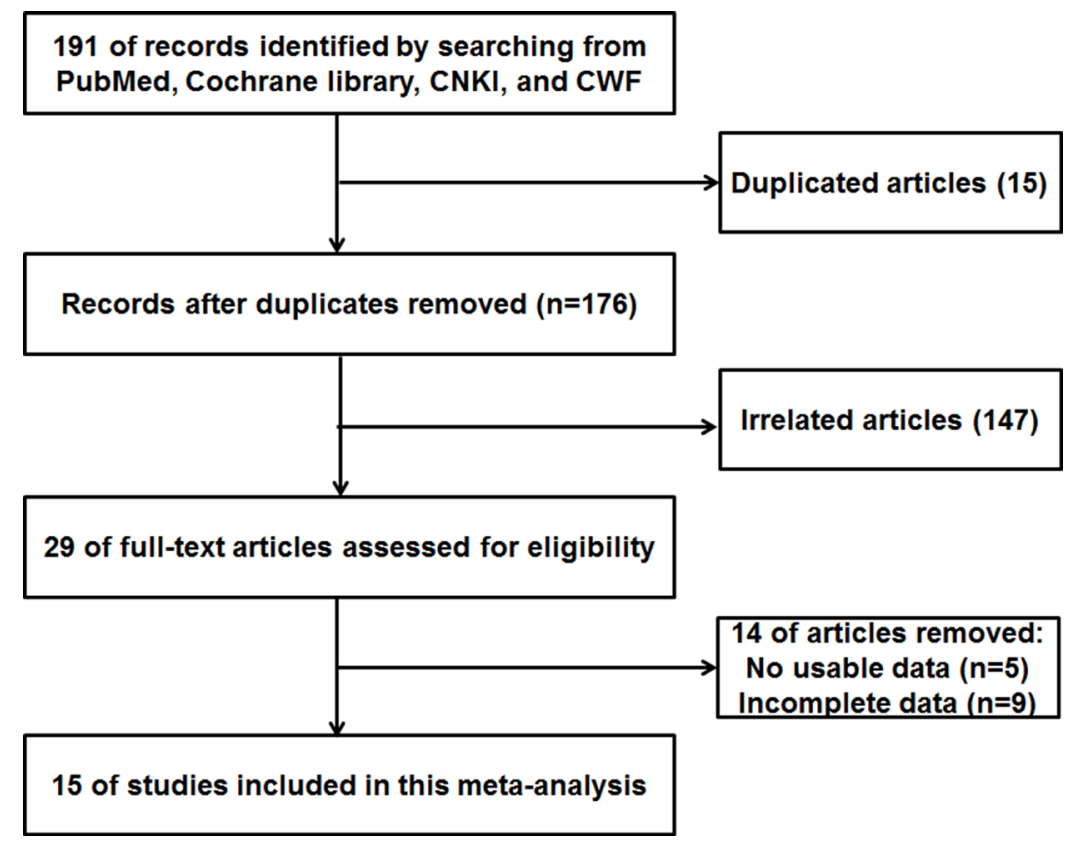

Figure 1: The flow diagram indicated the process of study selection. 
Table 1: Basic information of included studies

\begin{tabular}{|c|c|c|c|c|c|c|c|c|c|c|}
\hline Study ID & LncRNA & Country & $\begin{array}{l}\text { Dominant } \\
\text { ethnicity }\end{array}$ & Sample & Reference & $\begin{array}{c}\text { Detection } \\
\text { method }\end{array}$ & $\begin{array}{c}\text { Sample } \\
\text { size }\end{array}$ & Outcome & Source of HR & Cut off value \\
\hline Lingmin Liao 2014 & XLOC_010588 & China & Asian & tissue & GAPDH & qRT-PCR & 218 & OS/DFS & Reported\&SC & median \\
\hline Long Huang 2014 & HOTAIR & China & Asian & tissue & GAPDH & qRT-PCR & 218 & OS/DFS & Reported\&SC & median \\
\hline Jing Li 2014 & HOTAIR & China & Asian & tissue & GAPDH & qRT-PCR & 118 & OS/RFS & $\mathrm{SC}$ & median \\
\hline Shihong Cao 2014 & GAS5 & China & Asian & tissue & RNU6B & qRT-PCR & 102 & OS & Reported & 0.29 \\
\hline L. Yang 2015 & MALAT1 & China & Asian & tissue & GAPDH & qRT-PCR & 104 & OS/RFS & Reported\&SC & 3.075 \\
\hline Meng Yang 2015 & CCHE1 & China & Asian & tissue & RPS18 & qRT-PCR & 182 & OS/RFS & $\mathrm{SC}$ & median \\
\hline Reiko Kobayashi 2015 & XIST & Japan & Asian & tissue & GAPDH & qRT-PCR & 49 & OS & Reported & median \\
\hline Hee Jung Kim 2015 & HOTAIR & Korea & Asian & tissue & U6 & qRT-PCR & 111 & OS & Reported & 30-fold \\
\hline Shan Jiang 2015 & LET & China & Asian & tissue & GAPDH & qRT-PCR & 94 & OS & Reported & mean \\
\hline Y.F. Wang 2016 & HULC & China & Asian & tissue & GAPDH & qRT-PCR & 244 & OS & Reported & median \\
\hline Shaorong Zhang 2016 & PVT1 & China & Asian & tissue & GAPDH & qRT-PCR & 90 & OS & $\mathrm{SC}$ & median \\
\hline Marissa Iden 2016 & PVT1 & America & Caucasian & tissue & RPS18 & qRT-PCR & 121 & OS & SC & median \\
\hline Hee Jung Kim 2016 & HOXA11 & Korea & Asian & tissue & U6 & qRT-PCR & 92 & OS & Reported & 227.5-fold \\
\hline Jun Zhang 2017 & MEG3 & China & Asian & tissue & $\beta$-actin & qRT-PCR & 72 & OS/RFS & Reported\&SC & median \\
\hline Dongli Zhang 2017 & ANRIL & China & Asian & tissue & GAPDH & qRT-PCR & 53 & OS & Reported & median \\
\hline
\end{tabular}

$<0.01$, random-effect) (Figure 4). From the forest plot, the increased expressions of HOTAIR, MALAT1 and CCHE1 correlated with a worse prognosis, the decreased expressions of XLOC_010588 and MEG3 were associated with a worse prognosis. With all the lncRNAs HOTAIR generate the highest HR of 2.98 [12]; by contrast, MEG3 exhibited the lowest HR of 0.16 [24].

\section{Publication bias and sensitivity analysis}

As shown in Figure 5, Begg's test was used to perform the publication bias, respectively. In our meta-analysis, Begg's test suggested there were no publication bias in all groups, owing to the values of $P>0.05$. Meanwhile, we used Stata11.0 software to carry

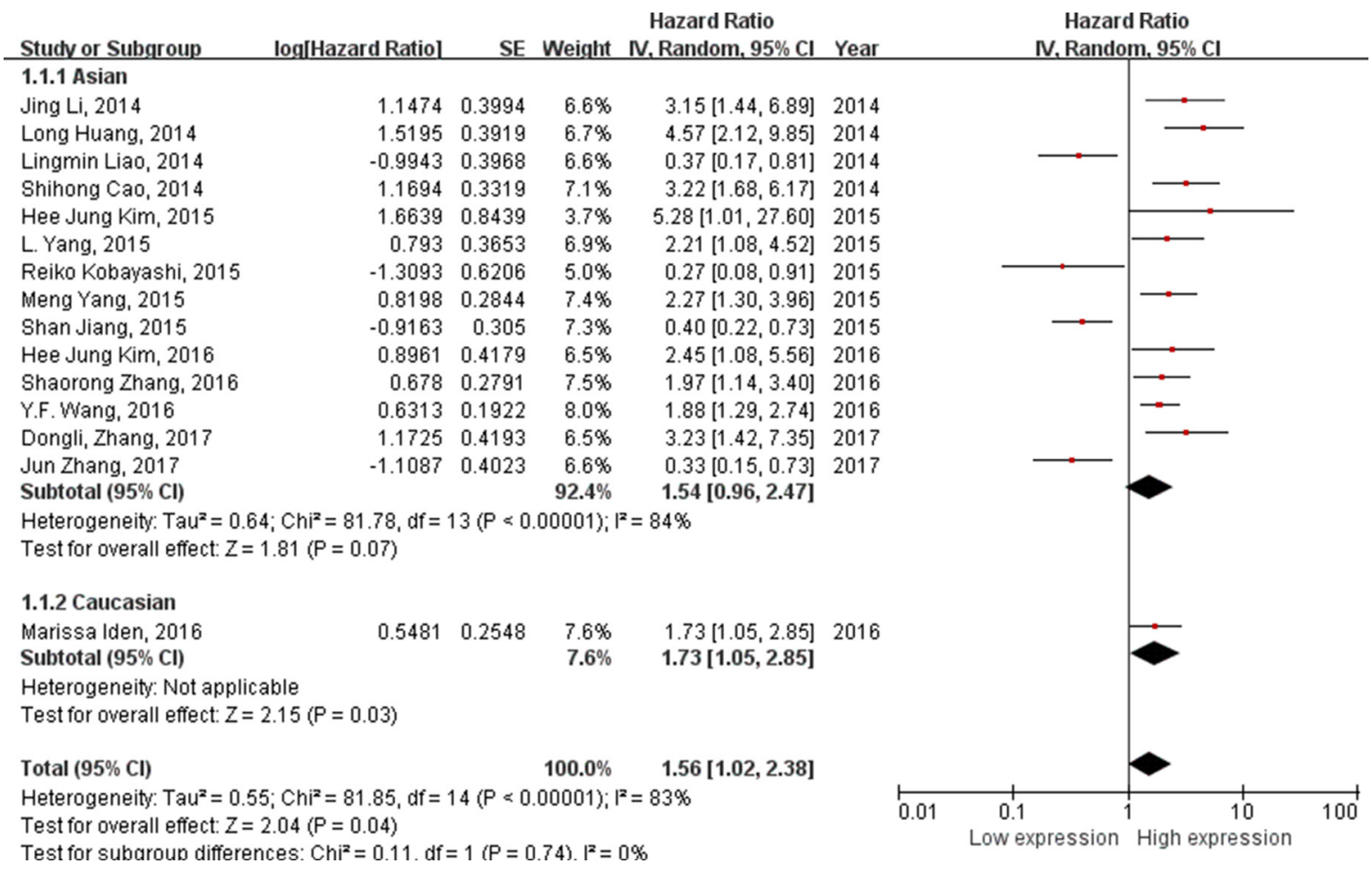

Figure 2: Forest plot of studies evaluating hazard ratios of IncRNAs expression and the overall survival in cervical. The point estimate is bounded by a $95 \%$ confidence interval, and the perpendicular line represents no increased risk for the outcome. 
Table 2: Summary of hazard ratios of IncRNA expression in cervical cancer

\begin{tabular}{|c|c|c|c|c|c|c|c|}
\hline \multirow[b]{2}{*}{ IncRNAs } & \multirow[b]{2}{*}{ Reference } & \multicolumn{2}{|c|}{ Case number } & \multicolumn{2}{|l|}{ OS } & \multicolumn{2}{|c|}{ DFS/RFS } \\
\hline & & $\begin{array}{c}\text { High } \\
\text { expression }\end{array}$ & $\begin{array}{c}\text { Low } \\
\text { expression }\end{array}$ & HR $(95 \%$ CI $)$ & $P$ Value & HR $(95 \%$ CI $)$ & $P$ Value \\
\hline HOTAIR & Long Huang, 2014 & 109 & 109 & $4.57(2.12-9.85)$ & $<0.001$ & $2.98(1.62-5.45)^{*}$ & 0.0004 \\
\hline HOTAIR & Jing Li, 2014 & 59 & 59 & $3.15(1.44-6.88)^{*}$ & 0.004 & $2.11(1.18-3.77)^{*}$ & 0.012 \\
\hline HOTAIR & Hee Jung Kim, 2015 & 89 & 22 & $5.28(1.01-27.75)$ & 0.049 & NM & NM \\
\hline PVT1 & Shaorong Zhang, 2016 & 45 & 45 & $1.97(1.14-3.40)^{*}$ & 0.015 & NM & NM \\
\hline PVT1 & Marissa Iden, 2016 & 63 & 58 & $1.73(1.05-2.84)^{*}$ & 0.03 & NM & NM \\
\hline XLOC_010588 & Lingmin Liao, 2014 & 109 & 109 & $0.37(0.17-0.75)$ & 0.006 & $0.45(0.25-0.83)^{*}$ & 0.008 \\
\hline GAS5 & Shihong Cao, 2014 & 58 & 44 & $3.22(1.68-6.17)$ & $<0.001$ & NM & NM \\
\hline MALAT1 & L. Yang, 2015 & 52 & 52 & $2.21(1.08-4.56)$ & 0.031 & $2.60(1.60-4.23)^{*}$ & 0.0001 \\
\hline CCHE1 & Meng Yang, 2015 & 91 & 91 & $2.27(1.30-3.96)^{*}$ & 0.004 & $1.23(1.10-1.38)^{*}$ & 0.0004 \\
\hline XIST & Reiko Kobayashi, 2015 & 24 & 25 & $0.27(0.08-0.86)$ & 0.027 & NM & NM \\
\hline LET & Shan Jiang, 2015 & 44 & 50 & $0.40(0.22-0.73)$ & 0.003 & NM & NM \\
\hline HULC & Y.F. Wang, 2016 & 120 & 124 & $1.88(1.29-2.74)^{*}$ & 0.001 & NM & NM \\
\hline HOXA11 & Hee Jung Kim, 2016 & 41 & 51 & $2.45(1.08-5.56)$ & 0.032 & NM & NM \\
\hline MEG3 & Jun Zhang, 2017 & 36 & 36 & $0.33(0.15-0.72)^{*}$ & 0.005 & $0.16(0.03-0.92)$ & 0.04 \\
\hline ANRIL & Dongli Zhang, 2017 & 27 & 26 & $3.23(1.42-7.32)^{*}$ & 0.005 & NM & NM \\
\hline
\end{tabular}

out sensitivity analysis to assess whether the individual studies affected the overall results. The results suggested that individual study had little influence on our eventual outcome (Figure 6), and proved that our analysis was relatively stable and credible.

\section{DISCUSSION}

Cervical cancer is one of the leading causes of cancer related death in women worldwide [26]. Identification of effective disease biomarkers for prognosis is urgently required. In recent years, mounting epidemiological and molecular biological studies have demonstrated that IncRNAs dysregulation was involved in cancers [27-29]. Furthermore, abnormal expression of multiple lncRNAs was found to be related with the tumorigenesis and may have the potential to be prognostic biomarkers and even therapeutic targets of cervical cancer [15, 30]. Therefore, we perform this meta-analysis to evaluate the prognostic ability of lncRNAs in cervical cancer.

Up to present, two meta-analysis [30,31] assessed the correlation between lncRNAs and cancer survival involved cervical cancer as one of the cancer sites. Both

\section{A} Study or Subgroup log[Hazard Ratio] SE Weight IV, Fixed, $95 \% \mathrm{Cl}$ Year

Long Huang, $2014 \quad \begin{array}{lllllll}1.5195 & 0.3919 & 45.9 \% & 4.57 & {[2.12,9.85]} & 2014\end{array}$

Jing Li, 2014

Hee Jung Kim, 2015

$1.1474 \quad 0.3994$

1.66390 .8439

Total $(95 \% \mathrm{Cl})$

Heterogeneity: $\mathrm{Chi}^{2}=0.58, \mathrm{df}=2(\mathrm{P}=0.75) ; \mathrm{I}^{2}=0 \%$

Test for overall effect: $Z=5.16(P<0.00001)$

$100.0 \% \quad 3.93[2.34,6.62]$

$44.2 \% \quad 3.15[1.44,6.89] 2014$

$9.9 \% 5.28[1.01,27.60] 2015$

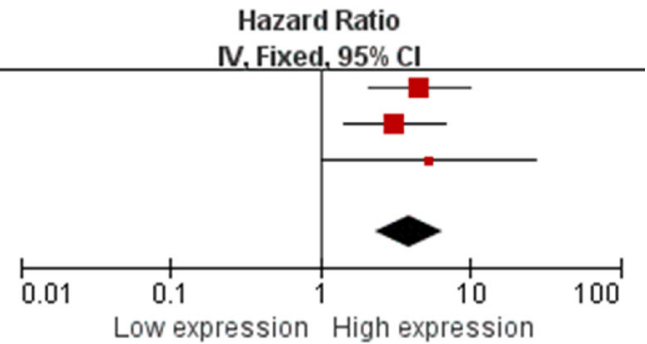

B

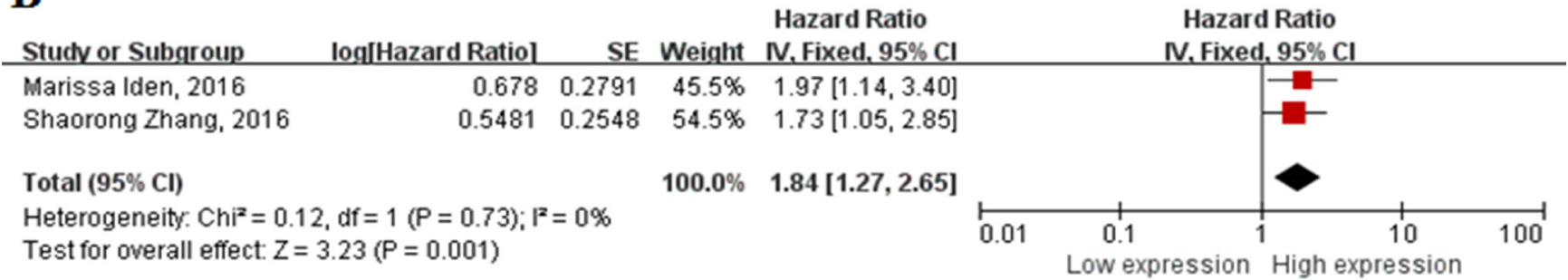

Figure 3: Forest plot of studies evaluating hazard ratios of up-regulated IncRNAs and the overall survival of cervical cancer. (A) HOTAIR; (B) PVT1. 
of these two studies focused on exploring a single lncRNA (H19 or HOTAIR) in relation to cervical cancer. With very different goal, our article mainly aimed to evaluate the prognosis ability of all lncRNAs in cervical cancer. Therefore, the current meta-analysis is the first to evaluate the relation between lncRNAs expression and prognosis of patients with cervical cancer comprehensively.

In current meta-analysis, we evaluated the prognostic value of lncRNAs in cervical cancer. Our results suggested that high expression of 1 cRNAs represented a risk factor

\begin{tabular}{|c|c|c|c|c|c|c|c|c|c|c|}
\hline Study or Subgroup & log[Hazard Ratio] & SE & Weight & $\begin{array}{c}\text { Hazard Ratio } \\
\text { IV, Random, } 95 \% \mathrm{Cl}\end{array}$ & Year & & $\begin{array}{r}\text { Hazarc } \\
\text { IV, Rando }\end{array}$ & $\begin{array}{l}\text { d Ratio } \\
\mathrm{m}, 95 \% \mathrm{Cl}\end{array}$ & & \\
\hline Long Huang, 2014 & 1.0919 & 0.311 & $17.3 \%$ & $2.98[1.62,5.48]$ & 2014 & & & $\longrightarrow$ & & \\
\hline Jing Li, 2014 & 0.7467 & 0.2965 & $17.7 \%$ & $2.11[1.18,3.77]$ & 2014 & & & $\rightarrow-$ & & \\
\hline Lingmin Liao, 2014 & -0.7985 & 0.2999 & $17.6 \%$ & $0.45[0.25,0.81]$ & 2014 & & & & & \\
\hline Meng Yang, 2015 & 0.207 & 0.057 & $22.0 \%$ & $1.23[1.10,1.38]$ & 2015 & & & 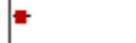 & & \\
\hline L. Yang, 2015 & 0.9555 & 0.2477 & $18.8 \%$ & $2.60[1.60,4.22]$ & 2015 & & & $\rightarrow$ & & \\
\hline Jun Zhang, 2017 & -1.8326 & 0.8925 & $6.7 \%$ & $0.16[0.03,0.92]$ & 2017 & & & & & \\
\hline Total $(95 \% \mathrm{Cl})$ & & & $100.0 \%$ & $1.33[0.77,2.28]$ & & & & & & \\
\hline \multicolumn{6}{|c|}{$\begin{array}{l}\text { Heterogeneity: } \text { Tau }^{2}=0.34 ; \text { Chi }^{2}=36.48, d f=5(P<0.00001) ; I^{2}=86 \% \\
\text { Test for overall effect: } Z=1.03(P=0.30)\end{array}$} & 0.01 & $\begin{array}{c}0.1 \\
\text { Low expression }\end{array}$ & ${ }^{1}$ High expr & $\begin{array}{l}10 \\
\text { ression }\end{array}$ & 100 \\
\hline
\end{tabular}

Figure 4: Forest plot $f$ studies evaluating hazard ratios of IncRNAs expression and the event free survival in cervical cancer. The point estimate is bounded by a $95 \%$ confdence interval, and the perpendicular line represents no increased risk for the outcome.
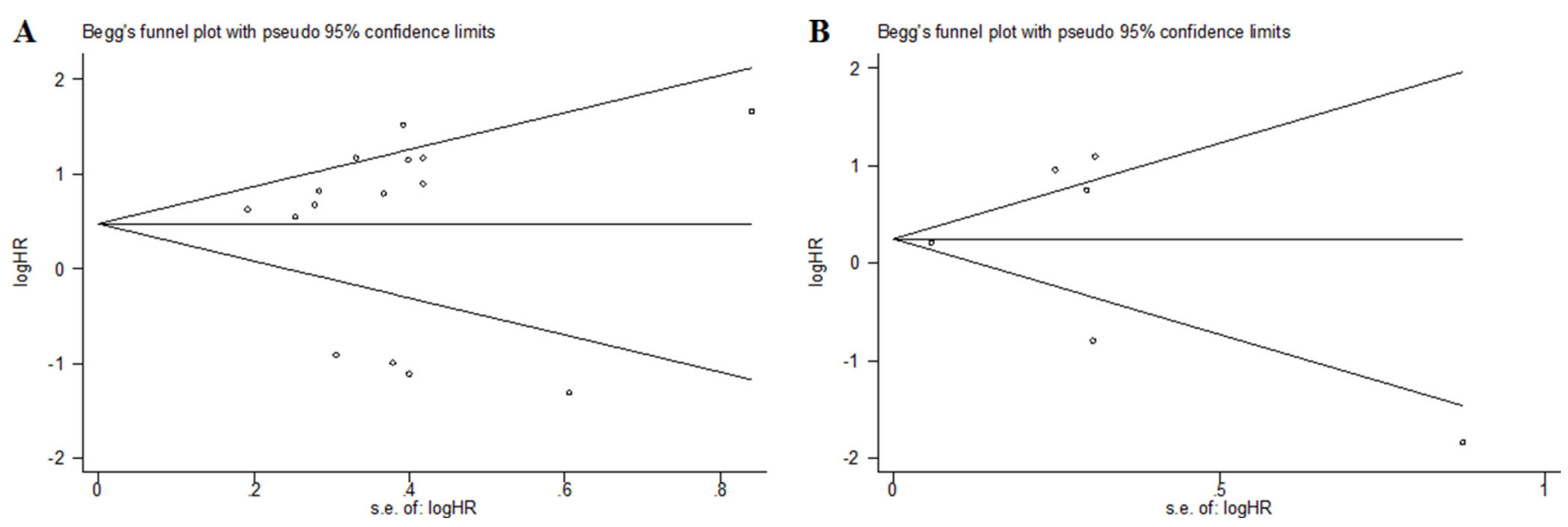

Figure 5: Begg's test for publication bias. (A) overall survival; (B) event free survival.
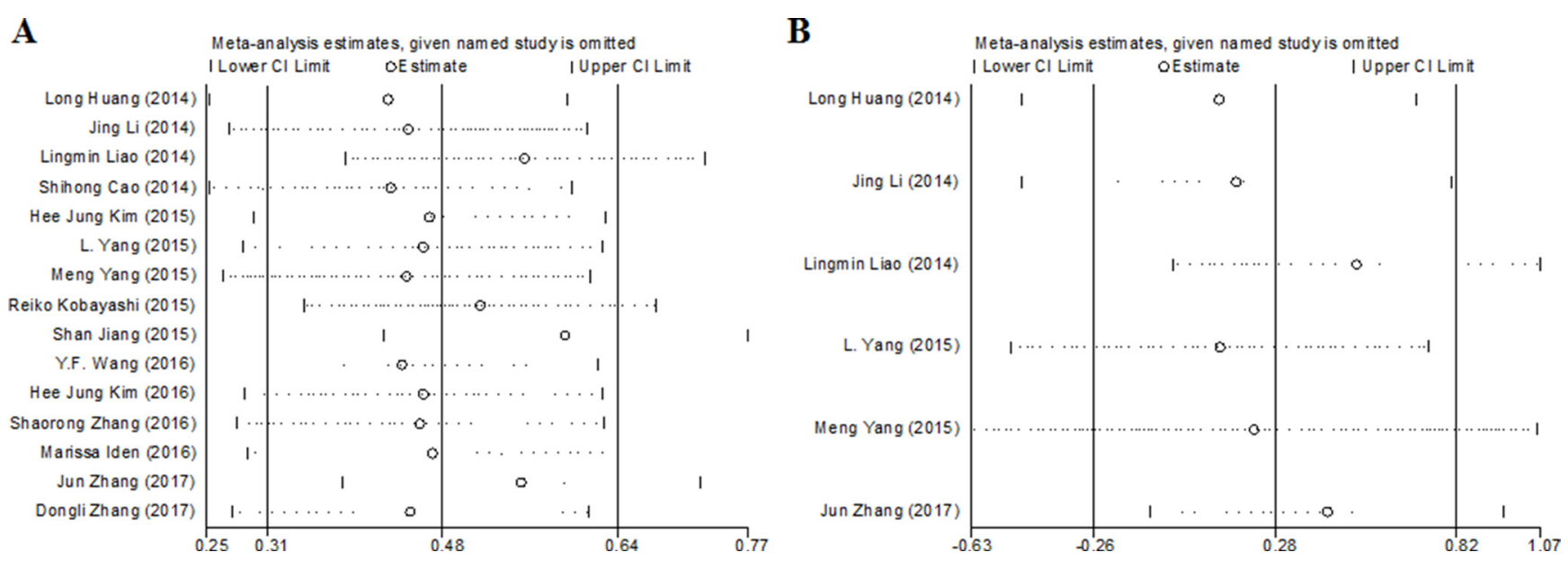

Figure 6: Sensitivity analyses of the studies. (A) overall survival; (B) event free survival. 
for OS and cervical cancer. Furthermore, we found that the high expressions of 8 lncRNAs were associated with poor prognosis. Besides, 4 lncRNAs were correlated to poor prognosis with the low expressions of lncRNAs in cervical cancer. Moreover, stratified analyses were performed using studies with the ethnicity. 14 articles reported the relationship between IncRNAs and Asian patents' OS (HR $=1.54$, , and 1article was about Caucasian $(\mathrm{HR}=1.73)$. Besides, EFS analysis also revealed a protective role decreased lncRNAs expression ( $\mathrm{HR}=1.33$ ). Our results suggested that the expression of these lncRNAs may have a significantly prognosis value in cervical cancer. Due to the limitation of the study number, these conclusions need more clinical trials for verification.

In the enrolling studies, PVT1 and HOTAIR were investigated in two or more articles, and with the increased expression of the two lncRNAs, the prognosis rate was poor in cervical cancer. Our results revealed that PVT1 is increased in the cervical cancer patients, and the high expression of PVT1 was related with the poor prognostic outcome of cancer patients. Summary of Hazard ratios (HRs) of lncRNAs in cervical cancer patients showed that HOTAIR generate the highest HR of 5.28. HOTAIR was the first lncRNA found to be involved in tumor and has been proven to be raised in a variety of human cancers [32]. Meanwhile, HOTAIR is a tumorigenic factor and can be adopted as a diagnosis or predictive biomarker in various cancer types $[33,34]$, those findings in consist with our results. Notably, HOTAIR was the most investigated lncRNA in cervical cancer, therefore, articles explored HOTAIR as a new biomarker in the diagnosis and treatment of cervical cancer is possibly the most promising.

It should be stressed that there were limitation in our analysis. First, the number size of eligible articles is relatively small, which restrict our ability to evaluate the prognosis of lncRNAs in subgroup analyses. Second, the main ethnicities of the patients in our analysis were Asian, which also might affect the results. Third, due to positive results could be published more easily than negative results, this may lead to hidden publication bias.

In summary, the current meta-analysis was firstly to evaluate the correlation between lncRNAs and prognosis of patients with cervical cancer. Despite these limitations, there was a relationship between lncRNAs levels and OS and EFS in cervical cancer, which demonstrated the strong prognostic value of lncRNAs in cervical cancer. However, large-scale and comprehensive studies were needed to confirm our findings and thus promote the clinical utility of lncRNAs in cervical cancer prognosis evaluation.

\section{MATERIALS AND METHODS}

\section{Search strategy}

A comprehensive search was performed independently by two researchers (Xiangrong Cui and
Xuan Jing) via PubMed, EMBASE and Web of Science for literatures published up to February 2017 to obtain relevant articles for the meta-analysis. The search strategy used both MeSH terminology and free text words to increase the sensitivity of the search. The keywords for the search in these databases included: "Long noncoding RNA", "IncRNA", "LincRNA", "Long ncRNA", "survival" and cervix (or cervical) cancer/neoplasm/ tumour/carcinoma. Meanwhile, we screened the references of retrieved relevant articles to identify potentially eligible literatures.

\section{Inclusion and exclusion criteria}

Literatures included in this meta-analysis had to meet the following inclusion criteria: studies about the association between IncRNAs expression in tissues or blood samples and prognosis of patients with cervical cancer; the survival outcomes were performed with OS or EFS including disease free survival DFS and RFS; patients were divided into high and low expression groups; sufficient published data were provided to calculate hazard ratios (HR) and 95\% confidence interval (CI). Exclusion criteria were as follow: studies without usable or sufficient data; laboratory articles, reviews, letters, unpublished data and conference abstracts.

\section{Data extraction}

Two investigators (Xiangrong Cui and Xuan Jing) extracted relevant data independently using predesigned and standardized form from the eligible studies. Extracted information included title, authors' names, the nationality and ethnicity of study population, lncRNAs, case number, methodological information and cut-off value. Disagreements were resolved through group discussion.

\section{Statistical methods}

HRs and 95\% CIs were calculated to assess to the relation between IncRNAs and survival in cervical cancer, with a significance level of $\alpha=0.05$. An observed HR $>1$ implied a worse survival for the group with elevated lncRNAs expression. Conversely, HR $<1$ implied a worse survival for the group with decreased lncRNAs expression $[35,36]$. We used Revman5.3 Software (Revman, the Cochrane Collaboration) to perform the meta-analysis and evaluate heterogeneity between studies by Cochrance $Q$-test and $P$-values. If heterogeneity was present ( $\mathrm{I}^{2} \geq 50 \%$ or $P \leq 0.05$ ), random-effect model was used to calculate pooled HRs or ORs, otherwise, the fixed-effect model was utilized [37, 38]. Furthermore, we minimized the influence of heterogeneity through classifying the included studies into subgroups accorded to similar features. The Stata 11.0 Software (Stata, College Station) was performed to evaluate the sensitivity and publication bias of the studies. Publication bias was estimated using 
Begg's test with a funnel plot, $P<0.05$ was considered statistically significant.

\section{ACKNOWLEDGMENTS AND FUNDING}

This work was supported by a grant from the Scientific Research Project of Shanxi Provincial Department of health (201601070).

\section{CONFLICTS OF INTEREST}

The authors declare no conflicts of interest.

\section{REFERENCES}

1. Jemal A, Bray F, Center MM, Ferlay J, Ward E, Forman D. Global cancer statistics. CA Cancer J Clin. 2011; 61:69-90.

2. Chandeying N, Hanprasertpong J. The prognostic impact of histological type on clinical outcomes of early-stage cervical cancer patients whom have been treated with radical surgery. J Obstet Gynaecol. 2017; 37:347-54.

3. Yoo W, Kim S, Huh WK, Dilley S, Coughlin SS, Partridge EE, Chung Y, Dicks V, Lee JK, Bae S. Recent trends in racial and regional disparities in cervical cancer incidence and mortality in United States. PLoS One. 2017; 12:e0172548.

4. Qi X, Shao M, Sun H, Shen Y, Meng D, Huo W. Long noncoding RNA SNHG14 promotes microglia activation by regulating miR-145-5p/PLA2G4A in cerebral infarction. Neuroscience. 2017; 348:98-106.

5. Cui X, Jing X, Long C, Tian J, Zhu J. Long noncoding RNA MEG3, a potential novel biomarker to predict the clinical outcome of cancer patients: a meta-analysis. Oncotarget. 2017; 8:19049-19056. https://doi.org/10.18632/ oncotarget. 14987.

6. Xu Z, Yan Y, Qian L, Gong Z. Long non-coding RNAs act as regulators of cell autophagy in diseases (Review). Oncol Rep. 2017; 37:1359-66. Review.

7. Chen R, Wang G, Zheng Y, Hua Y, Cai Z. Long non-coding RNAs in osteosarcoma. Oncotarget. 2017; 8:20462-20475. https://doi.org/10.18632/oncotarget.14726.

8. Wang J, Ye C, Xiong H, Shen Y, Lu Y, Zhou J, Wang L. Dysregulation of long non-coding RNA in breast cancer: an overview of mechanism and clinical implication. Oncotarget. 2017; 8:5508-5522. https://doi.org/10.18632/ oncotarget. 12537.

9. Liu Q, Guo X, Que S, Yang X, Fan H, Liu M, Li X, Tang H. LncRNA RSU1P2 contributes to tumorigenesis by acting as a ceRNA against let-7a in cervical cancer cells. Oncotarget. 2017; 8:43768-43781. https://doi.org/10.18632/ oncotarget.10844.

10. Yang L, Yi K, Wang H, Zhao Y, Xi M. Comprehensive analysis of lncRNAs microarray profile and mRNAlncRNA co-expression in oncogenic HPV-positive cervical cancer cell lines. Oncotarget. 2016; 7:49917-29. https://doi. org/10.18632/oncotarget.10232.

11. Cao S, Liu W, Li F, Zhao W, Qin C. Decreased expression of lncRNA GAS5 predicts a poor prognosis in cervical cancer. Int J Clin Exp Pathol. 2014; 7:6776-83.

12. Huang L, Liao LM, Liu AW, Wu JB, Cheng XL, Lin JX, Zheng M. Overexpression of long noncoding RNA HOTAIR predicts a poor prognosis in patients with cervical cancer. Arch Gynecol Obstet. 2014; 290:717-23.

13. Iden M, Fye S, Li K, Chowdhury T, Ramchandran R, Rader JS. The lncRNA PVT1 Contributes to the Cervical Cancer Phenotype and Associates with Poor Patient Prognosis. PLoS One. 2016; 11:e0156274.

14. Jiang S, Wang HL, Yang J. Low expression of long noncoding RNA LET inhibits carcinogenesis of cervical cancer. Int J Clin Exp Pathol. 2015; 8:806-11.

15. Kim HJ, Eoh KJ, Kim LK, Nam EJ, Yoon SO, Kim KH, Lee JK, Kim SW, Kim YT. The long noncoding RNA HOXA11 antisense induces tumor progression and stemness maintenance in cervical cancer. Oncotarget. 2016; 7:83001-83016. https://doi.org/10.18632/oncotarget.12863.

16. Kim HJ, Lee DW, Yim GW, Nam EJ, Kim S, Kim SW, Kim YT. Long non-coding RNA HOTAIR is associated with human cervical cancer progression. Int J Oncol. 2015; 46:521-30

17. Kobayashi R, Miyagawa R, Yamashita H, Morikawa T, Okuma K, Fukayama M, Ohtomo K, Nakagawa K. Increased expression of long non-coding RNA XIST predicts favorable prognosis of cervical squamous cell carcinoma subsequent to definitive chemoradiation therapy. Oncol Lett. 2016; 12:3066-74.

18. Li J, Wang Y, Yu J, Dong R, Qiu H. A high level of circulating HOTAIR is associated with progression and poor prognosis of cervical cancer. Tumour Biol. 2015; 36:1661-65.

19. Liao LM, Sun XY, Liu AW, Wu JB, Cheng XL, Lin JX, Zheng M, Huang L. Low expression of long noncoding XLOC_010588 indicates a poor prognosis and promotes proliferation through upregulation of c-Myc in cervical cancer. Gynecol Oncol. 2014; 133:616-23.

20. Wang YF, Zhang S, Li XQ, Wang Y. Expression of lncRNA HULC in cervical cancer and its correlation with tumor progression and patient survival. Eur Rev Med Pharmacol Sci. 2016; 20:3987-91.

21. Yang L, Bai HS, Deng Y, Fan L. High MALAT1 expression predicts a poor prognosis of cervical cancer and promotes cancer cell growth and invasion. Eur Rev Med Pharmacol Sci. 2015; 19:3187-93.

22. Yang M, Zhai X, Xia B, Wang Y, Lou G. Long noncoding RNA CCHE1 promotes cervical cancer cell proliferation via upregulating PCNA. Tumour Biol. 2015; 36: 7615-22.

23. Zhang D, Sun G, Zhang H, Tian J, Li Y. Long non-coding RNA ANRIL indicates a poor prognosis of cervical cancer 
and promotes carcinogenesis via PI3K/Akt pathways. Biomed Pharmacother. 2017; 85:511-16.

24. Zhang J, Lin Z, Gao Y, Yao T. Downregulation of long noncoding RNA MEG3 is associated with poor prognosis and promoter hypermethylation in cervical cancer. J Exp Clin Cancer Res. 2017; 36:5.

25. Zhang S, Zhang G, Liu J. Long noncoding RNA PVT1 promotes cervical cancer progression through epigenetically silencing miR-200b. APMIS. 2016; 124:649-658. https:// doi.org/10.1111/apm.12555.

26. Siegel R, Naishadham D, Jemal A. Cancer statistics, 2012. CA Cancer J Clin. 2012; 62:10-29.

27. Jin Y, Cui Z, Li X, Jin X, Peng J. Upregulation of long non-coding RNA PlncRNA-1 promotes proliferation and induces epithelial-mesenchymal transition in prostate cancer. Oncotarget. 2017; 8:26090-26099. https://doi. org/10.18632/oncotarget.15318.

28. Pei Z, Du X, Song Y, Fan L, Li F, Gao Y, Wu R, Chen Y, Li W, Zhou H, Yang Y, Zeng J. Down-regulation of lncRNA CASC2 promotes cell proliferation and metastasis of bladder cancer by activation of the Wnt/ $\beta$-catenin signaling pathway. Oncotarget. 2017; 8:18145-18153. https://doi. org/10.18632/oncotarget.15210.

29. Xia M, Yao L, Zhang Q, Wang F, Mei H, Guo X, Huang W. Long noncoding RNA HOTAIR promotes metastasis of renal cell carcinoma by up-regulating histone H3K27 demethylase JMJD3. Oncotarget. 2017; 8:19795-19802. https://doi.org/10.18632/oncotarget.15047.

30. Peng L, Yuan XQ, Liu ZY, Li WL, Zhang CY, Zhang YQ, Pan X, Chen J, Li YH, Li GC. High lncRNA H19 expression as prognostic indicator: data mining in female cancers and polling analysis in non-female cancers. Oncotarget. 2017; 8:1655-1667. https://doi.org/10.18632/oncotarget.13768.

31. Liu S, Zhang M, Qu P. Expression level and clinical significance of HOX transcript antisense intergenic RNA in cervical cancer: a meta-analysis. Sci Rep. 2016; 6:38047.
32. Gupta RA, Shah N, Wang KC, Kim J, Horlings HM, Wong DJ, Tsai MC, Hung T, Argani P, Rinn JL, Wang Y, Brzoska P, Kong B, et al. Long non-coding RNA HOTAIR reprograms chromatin state to promote cancer metastasis. Nature. 2010; 464:1071-76.

33. Ma MZ, Li CX, Zhang Y, Weng MZ, Zhang MD, Qin YY, Gong W, Quan ZW. Long non-coding RNA HOTAIR, a c-Myc activated driver of malignancy, negatively regulates miRNA-130a in gallbladder cancer. Mol Cancer. 2014; 13:156.

34. Hajjari M, Salavaty A. HOTAIR: an oncogenic long noncoding RNA in different cancers. Cancer Biol Med. 2015; 12:1-9.

35. Chen J, Chen Y, Gu L, Li X, Gao Y, Lyu X, Chen L, Luo G, Wang L, Xie Y, Duan J, Peng C, Ma X. LncRNAs act as prognostic and diagnostic biomarkers in renal cell carcinoma: a systematic review and meta-analysis. Oncotarget. 2016; 7:74325-74336. https://doi.org/10.18632/oncotarget.11101.

36. Jing W, Li N, Wang Y, Liu X, Liao S, Chai H, Tu J. The prognostic significance of long noncoding RNAs in nonsmall cell lung cancer: a meta-analysis. Oncotarget. 2017; 8:3957-3968. https://doi.org/10.18632/oncotarget.13956.

37. DerSimonian R, Laird N. Meta-analysis in clinical trials. Control Clin Trials. 1986; 7:177-88.

38. Mantel N, Haenszel W. Statistical aspects of the analysis of data from retrospective studies of disease. J Natl Cancer Inst. $1959 ; 22: 719-48$. 